\title{
Where is Computer Science Education Research Happening?
}

\author{
Stephanie Lunn ${ }^{*}$ \\ slunn002@fiu.edu \\ Florida International University \\ Miami, Florida
}

\author{
Maíra Marques Samary* \\ mairasamary@gmail.com \\ Boston College \\ Chestnut Hill, Massachusetts
}

\author{
Alan Peterfreund \\ apeterfreund@sagefoxgroup.com \\ SageFox Consulting Group \\ Amherst, Massachusetts
}

\begin{abstract}
Although computer science education (CSEd) is growing rapidly as a discipline, presently there are a limited number of formal programs available for students to pursue graduate degrees. To explore what options exist, we sought to develop a better understanding of the researchers and institutions currently working in CSEd. We collected publication data between 2015 and 2020 from the Innovation and Technology in Computer Science Education (ITiCSE) and ACM International Computing Education Research (ICER) conferences, and from the ACM Transactions on Computing Education (TOCE) journal. Using a total of 1,099 publications, we analyzed the authorship blocks and their affiliations. We created a comprehensive database, used for analysis on recent contributions to CSEd research. Among other findings, we observed that 2,068 distinct authors contributed, spanning 578 global institutions. From these, 963 of the authors came from 236 distinct universities in the United States. Moreover, we found that most often, new growth from international contributions resulted from the participation of additional universities, whereas in the United States most growth was the result of new contributors from the same universities. The results of this research are intended to encourage global collaborations, to provide an informative guide about recent publications in the field, and also to serve as a guidepost for graduate recruitment and further exploration into CSEd research and programs.
\end{abstract}

\section{CCS CONCEPTS}

- Social and professional topics $\rightarrow$ Computer science education.

\section{KEYWORDS}

Computing education, Computer science education, CSEd research

\section{ACM Reference Format:}

Stephanie Lunn, Maíra Marques Samary, and Alan Peterfreund. 2021. Where is Computer Science Education Research Happening?. In Proceedings of the 52nd ACM Technical Symposium on Computer Science Education (SIGCSE '21), March 13-20, 2021, Virtual Event, USA. ACM, New York, NY, USA, 7 pages. https://doi.org/10.1145/3408877.3432375

*Both authors contributed equally to this research.

Permission to make digital or hard copies of all or part of this work for personal or classroom use is granted without fee provided that copies are not made or distributed for profit or commercial advantage and that copies bear this notice and the full citation on the first page. Copyrights for components of this work owned by others than ACM must be honored. Abstracting with credit is permitted. To copy otherwise, or republish, to post on servers or to redistribute to lists, requires prior specific permission and/or a fee. Request permissions from permissions@acm.org.

SIGCSE '21, March 13-20, 2021, Virtual Event, USA

(C) 2021 Association for Computing Machinery.

ACM ISBN 978-1-4503-8062-1/21/03 .. \$15.00

https://doi.org/10.1145/3408877.3432375

\section{INTRODUCTION}

Computer science education (CSEd) is an emerging field that spans the disciplines of education, psychology, engineering, and computing (consisting of computer science, information technology, information science, and computer engineering) $[4,13,20]$. Such work is vital not only for training of K-12 CS teachers and university professors, but also to evaluate and improve the pedagogy of computing fields themselves $[9,19,31]$. Although research may be conducted in this area, and some courses may span this topic, there is limited information about what formal programs, faculty mentors, and course options exist for graduate students in the United States (U.S.) and abroad. However, as a first step, Dr. Amy J. Ko has made a laudable effort towards gathering such information and making it publicly available ${ }^{1}$. As a further means towards formally studying this topic, and with the eventual goal of developing support for such programs, it is imperative to find ways to evaluate where work in CSEd is produced.

For CSEd to grow as a discipline, it is important to examine the contributors, collaborations, and ongoing research, which manifests as publications. In this work, we sought to create a better understanding of the landscape of institutions and graduate students involved in CSEd research. To achieve this, we collected information from the proceedings of the ACM Innovation and Technology in Computer Science Education (ITiCSE) and ACM International Computing Education Research (ICER) conferences. In addition, we gathered affiliation information from the ACM Transactions on Computing Education (TOCE) journal. Using the authors and their institutional affiliations from the publications, we sought to answer the following research questions (RQs):

- RQ1: Which institutions are the most involved in CSed research globally?

- RQ2: Where are graduate students engaged in CSEd Research?

- RQ3: How has participation changed in CSEd, in terms of the contributions of unique authors and intuitions?

In this research, we operate under the assumption that these publication hubs serve as natural grounds for training new CSEd researchers. Accordingly, we are less concerned with categorizing what the publications are about or in creating and analysing clusters of authors [17], and more interested in learning about the authors' affiliations. This research is novel in that it applies a systematic approach to identify where CSEd research is being conducted, and more specifically the home institutions of the publishing graduate students. Although other studies may have profiled CSEd conference proceedings, they typically focus more on the content covered rather than the who and where the research is conducted $[10,25,26,29]$.

\footnotetext{
${ }^{1}$ http://faculty.washington.edu/ajko/cer
} 
Specifically, we analyze papers, posters, panels, working groups, tutorials, doctoral consortia, as well as tool and technique publications presented in ITiCSE and ICER conference proceedings, and journal publications from TOCE, between 2015 and July 2020. We pay particular attention to doctoral consortia, which are established for doctoral students in CSEd to give them a chance "to explore and develop their research interests in a workshop environment with a panel of established researchers" [2]. Ultimately, we intend for these findings to be a source of information that can be applied for general field-building and to promote more programmatic support for graduate students.

In this paper, we first present the related research in section 2. Then we describe the methods used to gather information about work conducted over the past 6 years, what was done to pre-process the data, and how we analyzed the collected data in section 3 . We present the results of this work in section 4 , and then discuss what these findings could mean in section 5 . Next, we present the limitations of this research in section 6. Finally, in section 7 we offer our conclusions and suggestions for future work.

\section{RELATED RESEARCH}

\subsection{CSEd Sources}

Although CSEd is still a growing discipline, a number of journals and conferences have arisen to allow researchers in this area a place to publish and to share their work. Among these, some of the top sources for CSEd researchers include [10, 15, 16, 22, 24]:

- ACM Transactions on Computing Education (TOCE)

- Computer Science Education Journal (CSEJ)

- ACM Conference on International Computing Education Research (ICER)

- ACM Conference on Innovation and Technology in Computer Science Education (ITiCSE)

- ACM Technical Symposium on Computer Science Education (SIGCSE)

- Australasian Computing Education Conference (ACE)

- IEEE Frontiers in Education (FIE) Conference

- Koli Calling International Conference on Computing Education Research

While this list may not include all sources for CSEd publications, the ones shown are described as "central forums" in this research area by Malmi, that offer a "good overview of the field" [12].

As a limited number of formal CSEd Ph.D. programs with comprehensive listings and established guidelines exist, we must find alternative ways to obtain information about where clusters of research are being conducted. In our study, we chose to investigate proceedings from ITiCSE and ICER, and journal publications from TOCE $[10,15]$. While authors in this field are likely to also publish in other venues, we wanted to keep the scope limited, but to also examine global progress in CSEd, to observe where research occurs. Moreover, these conferences enabled us to explore the graduate student contribution to CSEd since they offer doctoral consortia. This track in particular, may be reflective of where funding exists, where mentors for CSEd research reside, and potentially, of which institutions have formal Ph.D. programs.

\subsection{Reviewing Publications from CSEd Sources}

Although other researchers have previously analyzed CSEd publications as well, typically they focus on content classification or techniques rather than examining the authors or their affiliations $[10,21,23,25,26,29]$. In 2004, Valentine examined 20 years of technical symposiums from SIGCSE [29]. In addition to the observation that technical symposiums increased substantially during the 20 year time frame assessed, Valentine also categorized the presentations using informal labels like "Marco Polo" and "Nifty."

In 2007, Simon described a more systematic approach to classify computing education publications, leveraging the content of recent publications in CSEd from Australia and New Zealand [25]. This new method categorized work along formal dimensions based on topic, context, nature and scope. Then each dimension was further subdivided. For example, topic included 17 different groups, such as "Assessment tools" and "language/culture issues." Moreover, this system allowed researchers to distinguish between papers that focused on the practice of CSEd, and research on CSEd. As a measure of validity, Simon also compared the results of this new system to Valentine's prior analysis. In 2016, Simon further analyzed collaborations and authorship from ICER, to identify patterns over a span of 11 years [27]. Yet, this analysis focused more on the countries of origin and specific authors, rather than institutions. However, these types of bibliometrics proved critical to modeling formal analysis of CSEd publications [14, 27, 28].

In 2019, Hao et al. [10] examined publications in computing education from SIGCSE, ICER, ITiCSE, TOCE, and CSEJ to assess the amount of replication or repetition in CSEd publications. Using regular expressions to search for variants of the root "replicat," they found that only $2.38 \%$ of work conducted was a proper replication. Among the topics that were considered in replication studies, the bulk of work was conducted on learning and teaching strategies, followed by assessment.

Then in 2020, Simon and Sheard applied Simon's previous categorizations to analyze ITiCSE full papers and reports presented and published between 1996 and 2019 [26]. Again, they focused primarily on the content of the publications, and observed that programming education was the focus of the bulk of submission. Additionally, their examination revealed that more than half of the publications focused on work conducted in a single course, as opposed to topics that may span multiple classes or topics. Also, when considering the collaboration of the authors, they observed that the majority of full-paper publications included 2 or more authors from the same institution, followed by 2 or more institutions within the same country.

\section{METHODS}

To assess the current landscape in computing, we examined the conference proceedings from ITiCSE and ICER, and journal articles from TOCE between January 2015 and July 2020. An overview of the process employed is illustrated in figure 1, including the steps employed to collect, clean, and analyze the data. In total, we collected information that amounted to a total of 1,099 publications.

The authors manually selected information about the publication and the affiliations from the author block into a spreadsheet file. The information collected from each conference included the 


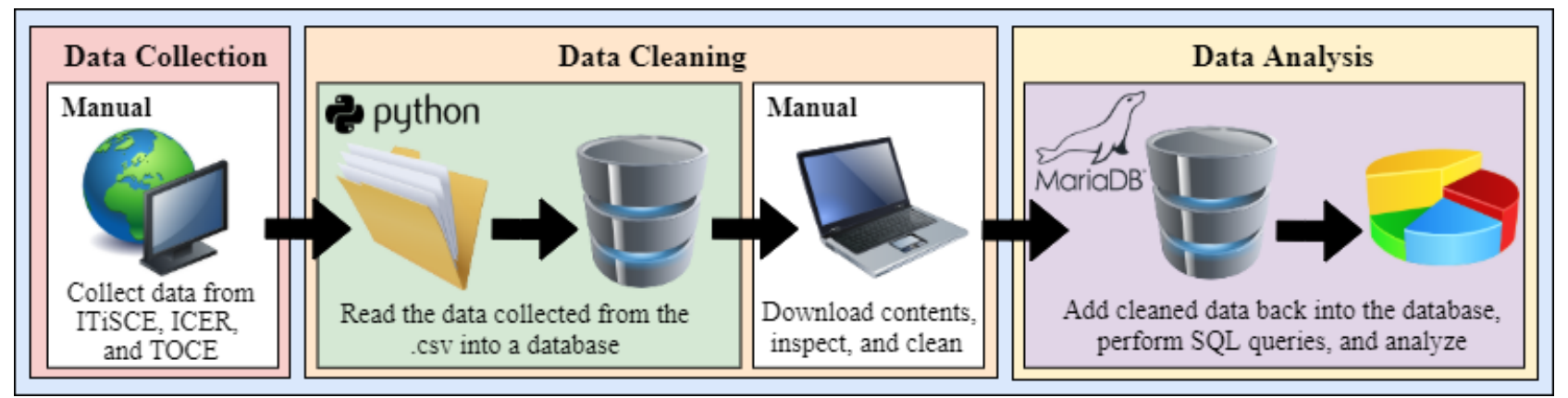

Figure 1: Overview of process from data collection to data analysis

title of the publication, the type of publication (e.g., paper, poster, panel, doctoral consortium), the author's (or authors') name(s), the institutional and/or organizational affiliation. Validity checking of the data was then performed by the first two authors. Moreover, while there were single author publications, particularly for the doctoral consortium, most publications included multiple authors. The total number of contributing authors went as high as 16 on a single publication.

Despite conferences having strict guidelines about templates used for publications, no such standards exist for the affiliations. Since the authorship and affiliation data was self-reported, they were often inconsistent in terms of the departments and the names of the corporate or academic affiliation. Even authors belonging to the same institution often would use different labels, e.g., Virginia Tech or Virginia Polytechnic Institute and State University. To eliminate overlap and ensure analogous titles were compared, we created a database to clean (and later analyze) the data. In addition, flags were given to each affiliation to separate commercial entities (like Google or Microsoft) and research institutions (like SageFox or WestEd) from universities. Only academic institutions/universities were included in the final counts.

We utilized version 10.4.13 of MariaDB [6], an open-source, relational tool, to create an SQL-based database of the publication records. To load data from the spreadsheet file, a parser was created to read each line and column of the spreadsheet, using Python. Specifically, we used the following Python libraries in this work: pandas, xlrd, mariadb, and postal.

Then, to ensure the names for domestic institutions were commensurate with formal titles, we compared with a database from the U.S. Department of Education, listing universities and college names. The process itself involved creating different combinations with the words used as affiliation gathered from the papers. This was done to be able to evaluate the correct name of any institution (we are comparing with an official database; we also used basic words normally used in names of institutions, such as "the," "at," "of" and other possible connectors). Meanwhile, we used a JSON file hosted and maintained on GitHub to parse the international university names based on email domains ${ }^{2}$.

Then, all of the cleaned data was re-added into the database to ensure the records reflected the proper institutional information. Using MariaDB, SQL was used to perform queries on the database.

\footnotetext{
${ }^{2}$ https://github.com/hipo/university-domains-list
}

We performed targeted searches to answer our research questions and to separate out the dataset by institution, type of publication (e.g., doctoral consortia), or by participation. All data was exported to a .csv file for final analysis.

\section{RESULTS}

In this section we provide an overview of the findings from our analysis on domestic CSEd research contributions. We first present a broad overview of the publications and acceptance rates in section 4.1. In section 4.2 , we further breakdown publications at the institutional level. Next, we consider graduate student contributions to doctoral consortia in section 4.3. Finally, we review participation, in terms of the unique authors and institutions that contribute over time in section 4.4 .

\subsection{Publications Overview}

The proceedings from ITiCSE and ICER, and journal articles from TOCE are available through the ACM digital library. In total, there were 1,099 publications between 2015 and 2020. From ITiCSE we had a total of 646 publications, from ICER 310 publications, and from TOCE 143 publications. In total, 2,068 distinct authors contributed to the venues we assessed, and among these, 963 (47\%) of those authors associated with institutions in the U.S.

It should be noted that the acceptance rate may play a role in how many publications existed each year. Although the percentages of accepted publications fluctuate annually, overall, ITiCSE has a $36 \%$ acceptance rate, and ICER has a $28 \%$ acceptance rate. Also, between 2019-2020 the impact factor of TOCE was last updated to 3.040 [1].

\subsection{Publications by Institution}

In total, 236 distinct universities from the U.S. contributed to these conferences. As illustrated in Table 1, we also examined which institutions have the most publications based on the authors' affiliations. Here, we only considered institutions domestically with more than 14 publications. We observed that the greatest counts came from North Carolina State University, followed by Georgia Institute of Technology, and then Michigan Technological University. We also explored the number of distinct authors producing work from each institution. Overall, Georgia Institute of Technology (34) had the highest count. In this table, we also indicate which institutions offer a graduate program (GP), and which are undergraduate only programs (UO). We suggest that UO institutions appearing with a high 


\begin{tabular}{|c|c|c|c|}
\hline $\begin{array}{c}\text { Institution and } \\
\text { Degrees Offered (UO or GP) }\end{array}$ & State & $\begin{array}{l}\text { \# of } \\
\text { Pub. }\end{array}$ & $\begin{array}{c}\text { \# of } \\
\text { Authors }\end{array}$ \\
\hline North Carolina State University (GP) & $\mathrm{NC}$ & 73 & 32 \\
\hline Georgia Institute of Technology (GP) & GA & 63 & 34 \\
\hline Michigan Technological University (GP) & MI & 51 & 19 \\
\hline $\begin{array}{l}\text { Virginia Polytechnic Institute and } \\
\text { State University (GP) }\end{array}$ & VA & 39 & 19 \\
\hline Carnegie Mellon University (GP) & PA & 36 & 20 \\
\hline University of Washington (GP) & WA & 33 & 16 \\
\hline University of California, San Diego (GP) & $\mathrm{CA}$ & 26 & 3 \\
\hline $\begin{array}{l}\text { University of Illinois at } \\
\text { Urbana-Champaign (GP) }\end{array}$ & IL & 25 & 23 \\
\hline Rochester Institute of Technology (GP) & NY & 22 & 14 \\
\hline Michigan State University (GP) & MI & 21 & 8 \\
\hline $\begin{array}{l}\text { University of California, } \\
\text { Santa Barbara (GP) }\end{array}$ & $\mathrm{CA}$ & 20 & 18 \\
\hline University of Colorado at Boulder (GP) & $\mathrm{CO}$ & 20 & 14 \\
\hline $\begin{array}{l}\text { University of North Carolina } \\
\text { at Charlotte (GP) }\end{array}$ & $\mathrm{NC}$ & 20 & 10 \\
\hline University of California, Berkeley (GP) & $\mathrm{CA}$ & 19 & 14 \\
\hline University of Nebraska, Lincoln (GP) & $\mathrm{NE}$ & 18 & 8 \\
\hline Knox College (UO) & IL & 17 & 5 \\
\hline University of Nebraska, Omaha (GP) & $\mathrm{NE}$ & 17 & 8 \\
\hline Villanova University (GP) & PA & 17 & 7 \\
\hline Clemson University (GP) & $\mathrm{CA}$ & 16 & 10 \\
\hline Ithaca College (UO) & NY & 16 & 7 \\
\hline Rhode Island College (UO) & RI & 16 & 2 \\
\hline Rice University (GP) & TX & 16 & 4 \\
\hline University of Florida (GP) & FL & 16 & 8 \\
\hline University of Chicago (GP) & IL & 15 & 7 \\
\hline University of Michigan Ann Arbor (GP) & MI & 15 & 9 \\
\hline
\end{tabular}

Note: GP- Graduate Program; UO- Undergraduate Only

Table 1: U.S.-based institutions with the most publications (abbreviated as pub.), between 2015 and 2020

number of publications may present an opportunity for recruitment for Ph.D. researchers in CSEd.

Additionally, we explored the amount of publications from international institutions; Among which, there were 578 institutions in total. As shown in Table 2, we again considered institutions with more than 14 publications. We found that the University of Toronto, in Canada, has the highest total number of publications (54). This is followed by two institutions in Australia, the University of Adelaide (38) and Monash University (35), respectively.

\subsection{Doctoral Consortia}

Doctoral consortia (DC) are valuable venues for graduate students to not only present their work, but also to receive feedback. They foster a sense of community, and provide support for developing a professional network.

To provide insight into the contribution of Ph.D. students, we considered doctoral consortia as a measure of where graduate research occurs. However, it should be noted that ICER held DC all six years examined, whereas DC only started at ITiCSE two years ago. Accordingly, over the entire time span that was available, we observe that there were 136 distinct contributions in total. However, when considering the continent where the home institution of the

\begin{tabular}{|l|l|c|}
\hline \multicolumn{1}{|c|}{ Institution } & Country & $\begin{array}{c}\text { \# of } \\
\text { Pub. }\end{array}$ \\
\hline University of Toronto & Canada & 54 \\
\hline The University of Adelaide & Australia & 38 \\
\hline Monash University & Australia & 35 \\
\hline University Of Helsinki & Finland & 28 \\
\hline Aalto University & Finland & 27 \\
\hline University of Auckland & New Zealand & 25 \\
\hline University of Newcastle & Australia & 26 \\
\hline Uppsala University & Sweden & 26 \\
\hline University College Dublin & UK & 22 \\
\hline Indian Institute of Technology Bombay & India & 20 \\
\hline The Robert Gordon University & UK & 19 \\
\hline $\begin{array}{l}\text { Norwegian University of Science } \\
\text { and Technology }\end{array}$ & Norway & 16 \\
\hline
\end{tabular}

Table 2: International institutions with the most publications (abbreviated as pub.), between 2015 and 2020

authors resides, as illustrated in figure 2, we observe that most often contributors to the doctoral consortium are from North America (57\%). However, roughly one-third (32\%), are also from Europe.

Furthermore, we also considered the institutional affiliations of student authors in the graduate consortia, since this is likely the best measure of where Ph.D. research in CSEd occurs. We present the breakdown by the number of student contributors in Table 3. While we did not display universities with 1 or 2 students, we do observe that Georgia Institute of Technology has the greatest number of students participating in these venues with 9 distinct publications at the doctoral consortia. Also, we found that these universities, which had 3 or more students represented, accounted for $41.2 \%$ of all the students accepted to the doctoral consortium. Furthermore, 15 universities have only one student participating over the whole time span, which may suggest isolated pockets of graduate students.

\subsection{Participation}

To develop an understanding of the growth in CSEd over the past 6 years, in terms of the contributions of unique authors and intuitions, we explored participation over time. In Table 4 and 5 we consider

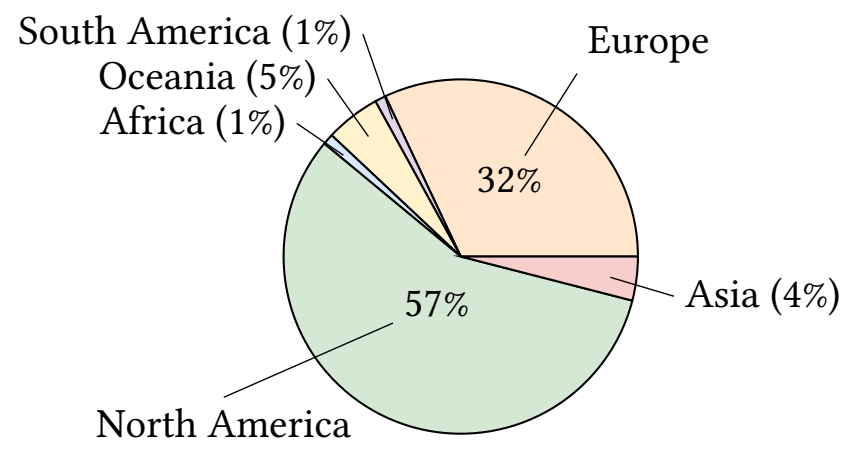

Figure 2: Continent of institutional origin for doctoral consortium students 


\begin{tabular}{|l|l|c|}
\hline \multicolumn{1}{|c|}{ Institution } & Country & Students \\
\hline Georgia Institute of Technology & US & 9 \\
\hline North Carolina State University & US & 6 \\
\hline University of Glasgow & UK & 6 \\
\hline University of Colorado At Boulder & US & 5 \\
\hline Michigan State University & US & 4 \\
\hline Indian Institute of Technology, Bombay & India & 4 \\
\hline Aalto University & Finland & 4 \\
\hline Virginia Polytechnic Institute and State University & US & 3 \\
\hline University of Washington & US & 3 \\
\hline University of Michigan & US & 3 \\
\hline Purdue University & US & 3 \\
\hline Worcester Polytechnic Institute & US & 3 \\
\hline University of Florida & US & 3 \\
\hline
\end{tabular}

Table 3: Student participation in the doctoral consortium by institution, country, and count

the changing participation as both a finite quantity and percentage. As an aside, we consider first time contributors as unique authors relative to authors who contributed in previous years. Likewise, first time institutions compared those institutions uniquely represented, relative to those that published in prior years.

Initially, we considered only authors and intuitions from the United States, as shown in Table 4. Over the past two years, we observe that the amount of unique contributors in publications has increased. Furthermore, there is a fairly stable average for first time contributors, which tends to be around $68 \%$. When considering institutional data, the amount of first time institutions publishing decreased from 2019 to 2020, but there was no overarching trend.

Next, we examined international participation sans the U.S., as shown in table 5 . When considering the entire time frame, we observed an increase in papers written by only one author. In addition, the increase of first time contributors has the same magnitude as the United States. However, when examining first time institutions, the averages of first time institutions averages around $54 \%$. This suggests that although the exact institutions participating may change over time, there is consistently new growth.

\section{DISCUSSION}

Our analysis provides a profile of work conducted at two major international conferences, as well as in a leading journal in CSEd. Gathering information from the affiliations in authorship blocks provided valuable insight into the domestic and international contributions. With the information provided we generated an empirical list of universities participating in CSEd research, such as North Carolina State University, Georgia Institute of Technology, and University of Toronto.

Although we were also interested in examining the schools and departments these authors belonged to, this proved problematic as many authors excluded such information. While we could not complete a detailed analysis with precise counts, we do know that participants came from a diverse set of departments - with computer science and education being the two largest. In the future, we recommend further investigation of the schools identified to better understand what academic programs the students belong to.

Overall, there is a tremendous amount of growth from new contributors, both internationally, and in the United States. Not only do

\begin{tabular}{|l|c|c|c|c|c|c|}
\hline \multicolumn{1}{|c|}{ Metric Assessed } & $\mathbf{2 0 1 5}$ & $\mathbf{2 0 1 6}$ & $\mathbf{2 0 1 7}$ & $\mathbf{2 0 1 8}$ & $\mathbf{2 0 1 9}$ & $\mathbf{2 0 2 0}$ \\
\hline \# of authors 1 publication & 138 & 139 & 179 & 168 & 237 & 246 \\
\hline \# of unique contributors & 162 & 170 & 223 & 210 & 296 & 286 \\
\hline \# first time contributors & - & 121 & 151 & 143 & 182 & 196 \\
\hline \% first time contributors & - & $71 \%$ & $68 \%$ & $68 \%$ & $61 \%$ & $69 \%$ \\
\hline $\begin{array}{l}\text { \# of unique institutions } \\
\text { represented }\end{array}$ & 77 & 83 & 102 & 83 & 128 & 99 \\
\hline \# of first time institutions & - & 46 & 49 & 25 & 44 & 23 \\
\hline \% of first time institutions & - & $55 \%$ & $48 \%$ & $30 \%$ & $34 \%$ & $23 \%$ \\
\hline
\end{tabular}

Table 4: Participation from the United States

\begin{tabular}{|l|c|c|c|c|c|c|}
\hline \multicolumn{1}{|c|}{ Metric Assessed } & $\mathbf{2 0 1 5}$ & $\mathbf{2 0 1 6}$ & $\mathbf{2 0 1 7}$ & $\mathbf{2 0 1 8}$ & $\mathbf{2 0 1 9}$ & $\mathbf{2 0 2 0}$ \\
\hline \# of authors 1 publication & 173 & 168 & 182 & 195 & 262 & 264 \\
\hline \# of unique contributors & 202 & 209 & 239 & 247 & 315 & 298 \\
\hline \# first time contributors & - & 164 & 158 & 167 & 217 & 200 \\
\hline \% first time contributors & & $78 \%$ & $66 \%$ & $68 \%$ & $69 \%$ & $67 \%$ \\
\hline $\begin{array}{l}\text { \# of unique institutions } \\
\text { represented }\end{array}$ & 90 & 106 & 117 & 97 & 135 & 142 \\
\hline \# of first time institutions & - & 80 & 62 & 43 & 63 & 70 \\
\hline \% of first time institutions & & $75 \%$ & $53 \%$ & $44 \%$ & $47 \%$ & $49 \%$ \\
\hline
\end{tabular}

Table 5: Participation from the international community

new contributors frequently appear between 2015 and 2020, but the numbers of first time institutions delineates that CSEd research continues to increase across the globe. In the U.S. approximately two thirds are first time contributors each year, although the number of first time institutions declines over our time frame. However, the percentage of first time institutions is still higher internationally. Taken together this suggests that growth in the U.S. is, in large part, the result of new authors within institutions already participating, whereas global growth is more often the result of newly engaged institutions. Given the expansion in the field, this signifies an opportunity for development and collaborations that reach across borders. Moreover, it presents a need to establish additional networks and communities to support the researchers in CSEd.

Having a designated community can be important. Previous research has demonstrated that isolation is a big concern for teachers in computer science at K-12 schools [11,31]. Often teachers cite this is due to a lack of peer support, and the types of community available for other departments, such as mathematics or English to share ideas, work through problems, or to discuss content [31]. Accordingly, creating such support networks are important not only for established teachers, but also for college students looking to get into this area [5, 7]. As programs currently stand, graduate students will be forced to either belong to a college of education where there may be limited knowledge of computer science or CSEd needs, or they will belong to computer science departments where there will be limited guidance on educational theories, or mentor-ship about resources that could be beneficial to their work.

Expecting students to exist in both worlds is not only challenging, but it leads to reduced understanding and quality of education surrounding the field. Although some progress has been made towards offering specific courses or towards considering interdisciplinary partnerships, the present attempts are insufficient in truly reconciling the topics. Moreover, often the courses are merely non-core or elective courses, and the programs generated fall under a general STEM education umbrella, which may fail to capture the nuances 
and concerns specific to computing education [3, 8, 9, 18, 30]. While we recognize that there are a slew of political barriers, it is imperative that we improve opportunities and collaborations. In order to foster communication between computer science and education, and partnerships across institutions, it is vital to create a community, or to consider the explicit creation of graduate programs, funding, and mentoring for both students and faculty in CSEd. Establishing such initiatives are imperative to advancing work in CSEd at the level of attention they deserve, and to meeting the needs of the workforce going forward.

In addition, we propose that graduate institutions should consider some of the undergraduate only schools as targets for recruitment efforts. Schools such as Knox College or Ithaca College could be sources of undergraduates looking to continue their research and work in CSEd. Knowing that they contribute to these global venues suggests that they may not only have an understanding of the field, but that they may contribute unique perspectives and peer support to graduate programs where others are just starting in the discipline for the first time.

\section{LIMITATIONS}

Although this work was meant to provide an exploratory overview of where work is conducted in CSEd, we acknowledge that there are several limitations. Firstly, we only considered two conferences and one journal, and computer science education researchers may publish in other venues, such as SIGCSE. Likewise, given the present field is hugely interdisciplinary without tailored departments or programs, researchers may also publish CSEd research in other fields, such as psychology, engineering, or education. We also only considered English language sources, and did not explore CSEd research published in events/journals in other languages.

In addition, we acknowledge that participation is based on acceptance and although actual submissions may be higher, our counts only reflect those that reviewers deemed appropriate. Moreover, when considering the institutions and authors that contribute to CSEd research over time, we acknowledge that funding may play a role as well. Since much of research, and graduate student support, is driven by financial opportunities and awards, lower attendance or publications in these settings may merely be reflective of restricted budgets rather than quantity or quality of research produced.

Furthermore, in terms of the publications obtained, we were only able to collect TOCE articles that had been published at the time of inquiry. Thus, the articles collected for 2020 only examined those published within and before volume 20, issue 3. Accordingly, other authors and institutions may have additional publications in this year after this time point.

Also the publication labels changed over time, which may have led to some variation in the precise counts. For example, in 2015, there were no publications explicitly labeled as "Tips, Techniques and Courseware." Although there may have been material that would have fit into this categorization, without clear identification, it was challenging to be certain. Alternatively, the label "Tools and Technologies in Computing Education” appeared in 2018 however, this was not a consistent label that appeared in other conference proceedings.

\section{CONCLUSION AND FUTURE WORK}

As CSEd continues to grow as an academic discipline, it is important to think about how to best prepare future teachers and researchers in this field. Although strides are being made to share research and develop programs globally, it is still important to consider how to better serve the target population. Institutionally, this may mean joint degree programs established between computer scientists and education, additional course offerings, or it could mean increased appointments of faculty knowledgeable on CSEd topics. At the country-wide level, this may mean offering support where resources may already be tight, and to institutions already at a critical mass. Moreover, collaborations are the utmost importance, not just within an institution or classroom, but between institutions across the globe.

In this work, we explored the authors who have contributed to TOCE, ICER, and ITiSCE between 2015 and 2020, and examined their affiliations with different organizations and/or institutions. Overall, there are a number of universities and individuals that conduct CSEd research, however, certain individuals and institutions tend to contribute more frequently. We observe that overall there is new growth in CSEd, although the pattern for the U.S. is different from that of the international universities. While globally we may see an increase in participation from the addition of new institutions, in the United States these increases are more likely the result of new authors contributing from the same institutions. However, we are unable to make assumptions about whether this effect is mediated primarily through faculty or student contributions, although this is something that could be explored with further investigation.

While not all the authors in publications included information about their school or department, going forward, it would be beneficial to find other ways to gather this information to obtain a better understanding of the profiles of those in CSEd. Uncovering counts of which departments authors reside in - such as computer science, education, engineering, the school of information, or psychology will offer valuable insight into the experiences of professors and graduate students, and the interdisciplinary collaborations that presently exist. To this end, it would also be helpful if there was a consistent format for institutional information, to make future work such as this easier. In addition, it would be beneficial to obtain a more comprehensive account of the experiences of Ph.D. students and faculty in CSEd going forward. Some options include conducting in depth interviews, or using surveys for those working in the field. Such methods could be useful tools for gaining insight not only into the existing systems, but also into the challenges these groups face.

In the future, we also suggest expanding the conferences searched to include SIGCSE Technical Symposium, and other pertinent options. Moreover, we recommend consideration of other CSEd-related journals as well, like CSEJ. The more comprehensive the understanding of what presently exists, the easier it will be to identify programs and mentors for future students interested in the field, and for researchers looking to form collaborations. As CSEd continues to grow, it is also necessary to develop a community and to equip students with the knowledge they need to succeed in the field. 


\section{ACKNOWLEDGMENTS}

We would like to thank the entire team at SageFox for their assistance on this work. Funding for this research was made possible by the National Science Foundation (Award \#1939265). Any opinions, findings, and conclusions or recommendations expressed in this material are those of the author(s) and do not necessarily reflect the views of the National Science Foundation.

\section{REFERENCES}

[1] 2020. ACM Transactions on Computing Education Journal Impact 2019-20: Metric, Prediction \& Ranking. https://academic-accelerator.com/Impact-FactorIF/ACM-Transactions-on-Computing-Education-TOCE

[2] 2020. Doctoral Consortium. https://icer.acm.org/track/icer-2020-doctoralconsortium

[3] Bulent Dogan and Susie Gronseth. 2019. Bringing out the "T" in STEM Education In STEM Education 2.0. Brill Sense, 153-174.

[4] Sally Fincher and Marian Petre. 2004. Computer science education research. CRC Press.

[5] Robin Flatland, Ira Goldstein, MaryAnne L Egan, Scott Vandenberg, Meg Fryling, and Sharon Small. 2018. Connecting colleges/universities and local high schools: A new model for high school cs teacher development. In Proceedings of the 49th ACM Technical Symposium on Computer Science Education. 958-963.

[6] MariaDB Foundation. 2020. About MariaDB Server. https://mariadb.org/about/

[7] Mark Guzdial. 2015. Learner-centered design of computing education: Research on computing for everyone. Synthesis Lectures on Human-Centered Informatics 8 , 6 (2015), 1-165.

[8] Mark Guzdial and Briana Morrison. 2016. Growing computer science education into a STEM education discipline. Commun. ACM 59, 11 (2016), 31-33.

[9] Susanne Hambrusch, Alan Peterfreund, Aman Yadav, and Amy Ko. 2020. Graduate Programs in CS Education: Why 2020 is the Right Time. In Proceedings of the 51st ACM Technical Symposium on Computer Science Education. 1407-1407.

[10] Qiang Hao, David H Smith IV, Naitra Iriumi, Michail Tsikerdekis, and Amy J Ko. 2019. A systematic investigation of replications in computing education research. ACM Transactions on Computing Education (TOCE) 19, 4 (2019), 1-18.

[11] Yasmin B Kafai, Jake Baskin, Deborah Fields, Joanna Goode, Bryan Twarek, and Aman Yadav. 2020. Looking Ahead: Professional Development Needs for Experienced CS Teachers. In Proceedings of the 51st ACM Technical Symposium on Computer Science Education. 1118-1119.

[12] Lauri Malmi. 2015. Supervisor's perspective. ACM Inroads 6, 2 (2015), 27-28.

[13] Lauri Malmi, Judy Sheard, Roman Bednarik, Juha Helminen, Päivi Kinnunen, Ari Korhonen, Niko Myller, Juha Sorva, and Ahmad Taherkhani. 2014. Theoretical underpinnings of computing education research: what is the evidence?. In Proceedings of the tenth annual conference on International computing education research. $27-34$.

[14] Lauri Malmi, Judy Sheard, Roman Bednarik, Juha Helminen, Ari Korhonen, Niko Myller, Juha Sorva, and Ahmad Taherkhani. 2010. Characterizing research in computing education: a preliminary analysis of the literature. In Proceedings of the Sixth international workshop on Computing education research. 3-12.
[15] Susana Masapanta-Carrión and J Ángel Velázquez-Iturbide. 2018. A systematic review of the use of Bloom's taxonomy in Computer Science education. In Proceedings of the 49th acm technical symposium on computer science education. 441-446.

[16] Sharon Mason. 2019. Examining the Nature of Collaborative Learning in the Context of Problem Solving in First-Year and Second-Year Computing Education, a Naturalistic Exploratory Case Study. Ph.D. Dissertation. State University of New York at Buffalo.

[17] Joe Miró Julià, David López, and Ricardo Alberich. 2012. Education and research: evidence of a dual life. In Proceedings of the ninth annual international conference on International computing education research. 17-22.

[18] Adams Nager and Robert D Atkinson. 2016. The case for improving US computer science education. Available at SSRN 3066335 (2016).

[19] Lijun Ni and Mark Guzdial. 2012. Who am I? understanding high school computer science teachers' professional identity. In Proceedings of the 43rd ACM technical symposium on Computer Science Education. 499-504.

[20] Justus J Randolph. 2007. Computer science education research at the crossroads: a methodological review of computer science education research, 2000-2005. Utah State University.

[21] Justus J Randolph, Roman Bednarik, and Niko Myller. 2005. A methodological review of the articles published in the proceedings of Koli Calling 2001-2004. In Proceedings of the 5th Annual Finnish/Baltic Sea Conference on Computer Science Education. Citeseer, 103-109.

[22] Justus J Randolph, George Julnes, Roman Bednarik, and Erkki Sutinen. 2007. A comparison of the methodological quality of articles in computer science education journals and conference proceedings. Computer Science Education 17, 4 (2007), 263-274.

[23] Kate Sanders, Judy Sheard, Brett A Becker, Anna Eckerdal, and Sally Hamouda. 2019. Inferential Statistics in Computing Education Research: A Methodological Review. In Proceedings of the 2019 ACM Conference on International Computing Education Research. 177-185.

[24] Lilian Passos Scatalon, Jeffrey C Carver, Rogério Eduardo Garcia, and Ellen Francine Barbosa. 2019. Software testing in introductory programming courses: A systematic mapping study. In Proceedings of the 50th ACM Technical Symposium on Computer Science Education. 421-427.

[25] Simon. 2007. A Classification of Recent Australasian Computing Education Publications. Computer Science Education 17, 3 (2007), 155-169.

[26] Simon and Judy Sheard. 2020. Twenty-Four Years of ITiCSE Papers. In Proceedings of the 2020 ACM Conference on Innovation and Technology in Computer Science Education. 5-11.

[27] A Simon. 2016. A Picture of the Growing ICER Community. In ICER. 153-159.

[28] Simon Simon et al. 2015. Emergence of computing education as a research discipline. (2015).

[29] David W Valentine. 2004. CS educational research: a meta-analysis of SIGCSE technical symposium proceedings. ACM SIGCSE Bulletin 36, 1 (2004), 255-259.

[30] Sara Vogel, Rafi Santo, and Dixie Ching. 2017. Visions of computer science education: Unpacking arguments for and projected impacts of CS4All initiatives. In Proceedings of the 2017 ACM SIGCSE Technical Symposium on Computer Science Education. 609-614.

[31] Aman Yadav, Sarah Gretter, Susanne Hambrusch, and Phil Sands. 2016. Expanding computer science education in schools: understanding teacher experiences and challenges. Computer Science Education 26, 4 (2016), 235-254. 